\title{
Pengembangan Puzzle Trigonometri untuk Meningkatkan Motivasi Belajar Matematika Siswa Sekolah Menengah Atas
}

\author{
Liya Nur Laili, Munika Saras Wati, Sekar Ayu Ramadhianti, Singgih Subiyantoro \\ Universitas Veteran Bangun Nusantara \\ Email: 1nur1249@gmail.com
}

\begin{abstract}
Abstrak
Penelitian ini bertujuan untuk mengembangkan media pembelajaran berupa alat peraga Puzzle Trigonometri yang layak dan tepat digunakan untuk meningkatkan motivasi dan pemahaman siswa kelas X Sekolah Menengah Atas pada pembelajaran matematika.. Prosedur penelitian dan pengembangan ini menggunakan ADDIE yaitu Analisis, menganalisis kebutuhan, materi dan peserta didik. Design, membuat rancangan media berupa gambar rencana alat peraga yang akan dibuat. Development, mengembangkan alat peraga ini dengan produksi lebih banyak. Implementasi, uji coba produk oleh ahli media dan ahli materi, serta uji coba pengguna oleh siswa dan guru. Evaluasi, dilakukan uji coba lapangan. Sasaran dalam penelitian ini adalah siswa kelas 10 SMA N 1 Weru, Sukoharjo. Data diambil menggunakan angket. Hasil penelitian menunjukkan bahwa pengembangan alat peraga Puzzle Trigonometri sebagai media pembelajaran layak digunakan, dan mampu meningkatkan motivasi dan pemahaman siswa pada materi trigonometri.
\end{abstract}

Kata Kunci : Matematika, Motivasi Belajar, Pemahaman, Puzzle Trigonometri

\section{Development of Trigonometry Puzzles for Improving Mathematics Learning Motivation for High School Students}

\author{
Liya Nur Laili, Munika Saras Wati, Sekar Ayu Ramadhianti, Singgih Subiyantoro \\ Universitas Veteran Bangun Nusantara \\ Email:Inur1249@gmail.com
}

\begin{abstract}
This study aims to develop learning media in the form of a proper and appropriate Trigonometry Puzzle teaching aid used to increase the motivation and understanding of high school class $X$ students in mathematics learning. This research and development procedure uses ADDIE, namely analysis, analyzing needs, material and students. Design, make a media design in the form of a picture of the props that will be made. Development, develop these teaching aids with more production. Implementation, product testing by media experts and material experts, and user trials by students and teachers. Evaluation, field trials were carried out. The targets in this study were 10th grade students of SMA N 1 Weru, Sukoharjo. Data was taken using a questionnaire. The results of the study showed that the development of Trigonometry Puzzle teaching aids as learning media was feasible, and was able to increase students' motivation and understanding of trigonometric material.
\end{abstract}

Keywords: Mathematics, Learning Motivation, Understanding, Trigonometry Puzzle 


\section{PENDAHULUAN}

Target implementasi Kurikulum 2013 salah satunya adalah perubahan pendidikan karakter yang terintregasi di sekolah, baik intrakurikuler, ekstrakurikler, maupun kokurikuler. Siswa dituntut untuk berpikir kritis, kreatif, komunikatif, dan kolaboratif. Perkembangan ilmu pengetahuan dan teknologi yang begitu pesat mendorong dunia pendidikan merespon dan mengikuti perkembangan itu secara cepat pula (Subiyantoro, 2019). Orientasi pengembangan kurikulum 2013 adalah tercapainya kompetensi yang berimbang antara sikap, keterampilan, dan pengetahuan, disamping metode pembelajarannya yang holistik dan menyenangkan (Suarga, 2017; Sugiyono dkk, 2014).

Saat ini masalah yang sering ditemukan dikalangan pelajar khususnya siswa SMA kelas $\mathrm{X}$ adalah motivasi belajar yang rendah. Motivasi belajar dapat menentukan baik tidaknya pencapaian belajar siswa sehingga semakin rendah motivasinya semakin sulit untuk mencapai keberhasilan belajar (Fauziyatun, 2014; Fauziah, 2017). Ciri siswa yang tidak memiliki motivasi belajar adalah tidak kritis dalam menanggapi masalah yang diberikan oleh guru saat proses pembelajaran berlangsung. Salah satu hal yang mengakibatkan hal ini terjadi adalah tidak adanya media pembelajaran yang mampu meningkatkan psikomotorik siswa.

Matematika merupakan salah satu mata pelajaran wajib yang ada di sekolah di seluruh Indonesia. Keberadaan mata pelajaran matematika ini membuat kebanyakan siswa khususnya siswa SMA merasa kesulitan. Matematika adalah subjek yang penting dalam kehidupan manusia, matematika berperan dalam hampir segala aspek bahkan di masa teknologi dan digital sekarang ini (Siregar, 2017; Falahudin, 2014). Selain itu matematika juga memiliki peran yang penting dalam berbagai disiplin serta untuk memajukan daya pikir manusia. Perkembangan pesat pada bidang teknologi informasi serta komunikasi saat ini dilandasi karena perkembangan matematika pada bidang teori bilangan, analisis, teori peluang, aljabar, serta diskrit. Agar dapat menguasai serta untuk menciptakan teknologi pada masa yang akan datang, maka diperlukan penguasaan dibidang matematika yang kuat sejak dini.

Sebagian siswa berpendapat bahwa pelajaran matematika merupakan pelajaran yang berat, sulit dimengerti, membosankan dan tidak menarik (Soleha, 2010). Tampilannya yang didominasi angka-angka membuat mebuat kebanyakan siswa tidak menyukai matematika. Sebuah penelitian menemukan hasil bahwa para subjek menganggap matematika sebagai mata pelajaran yang secara umum cukup sulit, dan belajar matematika yang menyenangkan adalah bermain game matematika (Siregar, 2017; Steffi, 2015; Nurcikawati, 2018). Salah satu materi pelajaran matematika SMA kelas 10 yang membuat peserta didik merasa kesulitan adalah materi trigonometri. Bagi para siswa tersebut, trigonometri identik dengan fungsinya yang meliputi sinus (sin), cosinus (cos), tangen $(\tan )$, cosecan $(\operatorname{cosec})$, secan (sec), dan cotangen (cotan). Pengaplikasian ilmu 
trigonometri ini dalam kehidupan mencakup berbagai bidang seperti astronomi, geografi, ekonomi, teknik, dan sebagainya.

Pada pembelajaran materi ini, banyak peserta didik banyak mengalami kesulitan. Apalagi media pembelajaran materi trigonometri yang sering ditemukan saat ini hanya berupa poster dan buku saja. Materi rumit dan didominasi rumus-rumus yang harus dihafalkan membuat siswa tersebut malas dan cepat merasa bosan saat mempelajari materi trigonometri. Ditambah lagi jika guru tidak tepat dalam memilih metode pembelajaran sehingga menjadi salah satu alasan utama siswa tidak dapat memahami materi ini dengan baik. Oleh karenanya, media pembelajaran inovatif menjadi sangat penting untuk dapat meningkatkan motivasi dan hasil belajar siswa (Octafiana, Ekosusilo, \& Subiyantoro, 2018).

Penelitian ini memiliki tujuan untuk mengembangkan inovasi media pembelajaran berupa Puzzle Trigonometri untuk meningkatkan motivasi belajar siswa pada mata pelajaran matematika khususnya materi trigonometri. Sehingga dapat meningkatkan motivasi dan minat belajar siswa khususnya siswa SMA kelas 10 terhadap materi trigonometri.

\section{METODE}

Metode yang digunakan dalam penelitian kali ini yaitu metode penelitian dan pengembangan (Research and Development) $R n D)$. Prosedur penelitian dan pengembangan ini menggunakan model ADDIE yaitu

\section{Analysis}

Tahap ini dilakukan penelitian dan pengumpulan informasi, meliputi tiga tahap antara lain : 1) Analisis kebutuhan sarana prasarana berupa alat dan bahan pembuatan puzzle,transportasi, dan konsumsi. 2) Analisis materi, dengan tujuan untuk meneliti ketersesuaian materi dalam Puzzle Trigonometri dengan materi trigonometri SMA kelas

\section{Design}

Tahap ini dilakukan penentuan konsep dari media pembelajaran. Media ini didesain sebagai alat bantu pembelajaran baik bagi guru maupun siswa. Hasil dari tahap ini adalah desain media berupa gambar rancangan alat peraga.

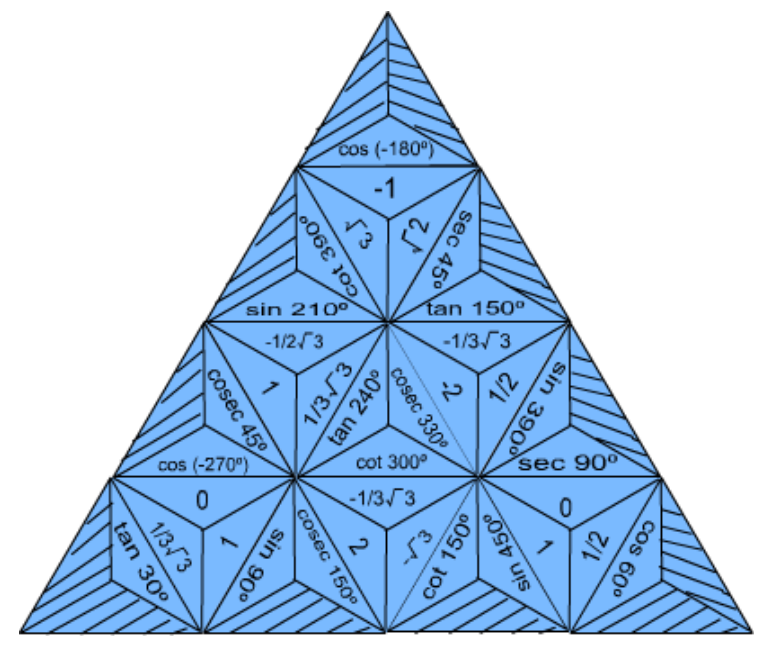

\section{Gambar 1. Rancangan Puzzle Trigonometri}

Berdasarkan design tersebut, diketahui bahwa soal dan jawaban terletak berpasangpasangan. Misal, hasil dari cos $\left(-180^{\circ}\right)$ adalah 1 , hasil dari sec $45^{\circ}$ adalah $\sqrt{2}$ hasil dari cot $390^{\circ}$ adalah $\sqrt{ } 3$ dan seterusnya sampai akhir. Oleh sebab itu jika ada kesalahan dalam pemasangan potongan puzzle maka akan 
membentuk rumusan yang salah.

\section{Develop}

Develop merupakan proses pengembangan design alat peraga yang sudah disusun sebelumnya. Di prosedur pengembangan ada dua tahap yaitu : 1) Tahap Produksi, proses pembuatan media sesuai dengan design. 2) Tahap penyelesaian, adalah tahap akhir atau penyelesaian dari pembuatan alat peraga PuzzleTrigonometri sebagai media pembelajaran matematika siswa SMA kelas 10.

\section{Implementation}

Media pembelajaran yang dihasilkan pada penelitian ini selanjutnya di uji coba kelayakan produk dan pengguna. Setiap penguji memberikan penilaian yang berbeda sesuai aspek keahliannya.

Berdasarkan uji ahli media pembelajaran, penguji sangat setuju bahwa design puzzle unik dan menarik, puzzle dikemas dengan rapi dan aman digunakan, kancingan penutup puzzle sudah sesuai, pegangan puzzle praktis dan efisien, puzzle mudah dibawa kemanamana, kayu yang digunakan dalam pembuatan puzzle memiliki kualitas yang bagus serta puzzle dikemas dengan rapi. Penguji juga setuju bahwa warna puzzle menarik, puzzle mudah digunakan dimanapun, mudah disimpan, mudah dibuka, mudah ditutup, materi jelas dan mudah dipahami, pewarnaan puzzle memenuhi standar kualitas, serta puzzle memiliki ukuran yang pas jika digunakan untuk 4-5 siswa. Penguji tidak setuju bahwa puzzle rumit untuk disusun, ukuran penutupnya tipis serta puzzle sulit disusun.
Penguji juga sangat tidak setuju bahwa penutup puzzle terlalu tipis.

Tabel 1. Persentase Hasil Penilaian oleh Ahli Media

\begin{tabular}{cc}
\hline Aspek Penilaian & Persentase (\%) \\
\hline Tampilan & 84 \\
Kemudahan & 75 \\
Kualitas & 87 \\
\hline Rata-rata & $\mathbf{8 2}$
\end{tabular}

Berdasarkan uji ahli media pembelajaran, penguji sangat setuju bahwa bahasa yang digunakan dalam puzzle sepenuhnya adalah bahasa matematika. Penguji setuju bahwa bahasa yang digunakan valid, soal dan jawaban bernilai benar, materi puzzle jelas dan mudah dipahami. Dan penguji tidak setuju bahwa terjadi kesalahan penulisan materi, penulisan huruf terlalu kecil, terdapat huruf yang sulit dipahami dan terdapat kesalahan penulisan huruf.

Tabel 2. Persentase Hasil Penilaian oleh Ahli Materi

\begin{tabular}{cc}
\hline Aspek Penilaian & $\begin{array}{c}\text { Persentase } \\
(\%)\end{array}$ \\
\hline Bahasa & 87,5 \\
Materi & 81 \\
Huruf & 75 \\
\hline
\end{tabular}

Pengujian selanjutnya dilakukan oleh ahli praktisi yaitu guru mata pelajaran matematika SMA dan siswa SMA kelas 10 . Pengguna menilai dari aspek media maupun materi yang meliputi materi, tata bahasa, dan kemanfaatan. Sistem uji coba dilakukan secara berkelompok 3-5 siswa untuk setiap satu puzzle. Berikut tabel persentase penilaian pengguna. 
Tabel 3. Persentase Hasil Penilaian oleh Ahli Praktisi Guru

\begin{tabular}{cc}
\hline Aspek Penilaian & Persentase (\%) \\
\hline Tampilan & 75 \\
Kemudahan & 78,5 \\
Kualitas & 75 \\
\hline Rata-rata & $\mathbf{7 6 , 1 6}$ \\
\hline
\end{tabular}

Tabel 4. Persentase Hasil Penilaian oleh Ahli Praktisi Siswa

\begin{tabular}{cc}
\hline Aspek Penilaian & Persentase (\%) \\
\hline Tampilan & 80 \\
Kemudahan & 82 \\
Kualitas & 87 \\
\hline Rata-rata & $\mathbf{8 6 , 3}$ \\
\hline
\end{tabular}

Persentase membuktikan bahwa alat peraga Puzzle Trigonometri sebagai media pembelajaran dilihat dari aspek tampilan, kemudahan penggunaan dan kualitas termasuk kedalam kategori baik dan layak diguanakan.

\section{Evaluation}

Uji coba lapangan dilakukan terhadap 30 siswa kelas 10 SMA N 1 Weru. Pada prosedur ini, penelitian dilakukan menggunakan data kualitatif, yaitu penelitian dengan menggunakan angket untuk mempermudah pengumpulan data. Pengguna disediakan angket berisi pernyataan yang mengacu pada aspek tampilan, aspek kemudahan dan aspek kualitas. Uji lapangan dilakukan untuk mengetahui tanggapan pengguna terhadap penggunaan alat peraga puzzle trigonometri. Berikut persentase yang diperoleh dari uji lapangan.
Tabel 5. Motivasi SiswaTerhadap Materi Trigonometri

\begin{tabular}{cc}
\hline Aspek Penilaian & Persentase (\%) \\
\hline Kesenangan & 84,6 \\
Minat & 75,8 \\
Semangat & 81 \\
\hline Rata-rata & $\mathbf{8 0 , 4 6}$ \\
\hline
\end{tabular}

Tabel 6. Pemahaman Siswa Terhadap Materi Trigonometri

\begin{tabular}{cccc}
\hline Kategori & Sebelum & Sesudah & Peningkatan \\
\hline Skor & 102 & 221 & 119 \\
Persentase & $34 \%$ & $71,2 \%$ & $37,2 \%$
\end{tabular}

Berdasarkan tabel persentase tersebut dapat dikatakan bahwa alat peraga Puzzle Trigonometri termasuk kriteria baik dan layak digunakan untuk media pembelajaran matematika.

\section{HASIL DAN PEMBAHASAN}

Berdasarkan langkah-langkah penelitian yang telah dilakukan, maka didapatkan media pembelajaran interaktif yang tepat dan layak digunakan oleh siswa SMA. Kelayakan tersebut didasarkan pada hasil penilaian ahli media, ahli materi, dan praktisi. Media ini digunakan untuk bahan mengajar guru dan bahan belajar mandiri siswa SMA kelas 10 . Produk yang dihasilkan dalam penelitian ini adalah alat peraga Puzzle Trigonometri. Indikator keberhasilan berupa angket pengguna yaitusiswa SMA kelas X. Berikut table motivasi siswa terhadap alat peraga Puzzle Trigonometri dan perbandingan pemahaman siswa sebelum dan sesudah penggunaan alat 
peraga Puzzle Trigonometri.

Tabel 7. Motivasi Siswa Terhadap Pembelajaran Materi Trigonometri

\begin{tabular}{cc}
\hline Aspek Penilaian & Persentase (\%) \\
\hline Kesenangan & 84,6 \\
Minat & 75,8 \\
Semangat & 81 \\
\hline Rata-rata & $\mathbf{8 0 , 4 6}$ \\
\hline
\end{tabular}

Tabel 8. Pemahaman Siswa Terhadap Materi Trigonometri

\begin{tabular}{cccc}
\hline Kategori & Sebelum & Sesudah & Peningkatan \\
\hline Skor & 102 & 221 & 119 \\
Persentase & $34 \%$ & $71,2 \%$ & $37,2 \%$ \\
\hline
\end{tabular}

Analisis uji efektivitas produik dimaksudkan agar produk yang dihasilkan efektif digunakan untuk pembelajaran matematika SMA yang mengarah ke aspek efektif, dan konigtif. Berdasarkan beberapa validasi yang telah dilakukan, maka terciptalah alat peraga Puzzle trigonometri untuk meningkatkan motivasi siswa terhadap pembelajaran matermatika khususnya materi trigonometri.

\section{KESIMPULAN}

Berdasarkan dari keseluruhan penelitian pengembangan alat peraga Puzzle Trigonometri sebagai media pembelajaran di Sekolah Menengah Atas dapat disimpulkan bahwa :1) Tercipanya alat peraga Puzzle Trigonometri yang tervalidasi sehingga tepat dan layak digunakan untuk media pembelajaran di Sekolah Menengah Atas.Alat peraga yang dibuat, dikembangkan melalui metode penelitian dan pengembangan (Research and Development/ RnD) dengan prosedur ADDIE. 2) Meningkatnya motivasi siswa terhadap pembelajaran matematika khususnya materi trigonometri.

Saran untuk penelitian lebih lanjut; perlu adanya media agar lebih variatif. Sedangkan saran untuk SMA yang dijadikan sebagai tempat sasaran kedepannya perlu dilengkapi alat pendukungsehingga kegiatan belajar mengajar lebih efektif.

\section{UCAPAN TERIMAKASIH}

Terimakasih kami sampaikan kepada Kemenristekdikti yang telah mendanai program ini, kepada Universitas Veteran Bangun Nusantara yang telah memfasilitasi, dan kepada SMA Negeri 1 Weru yang telah menjadi partner kerjasama penelitian.

\section{DAFTAR PUSTAKA}

Fauziyatun, N. N. 2014. Faktor-Faktor Yang Melatarbelakangi Rendahnya Motivasi Belajar Siswa Kelas Ix Smp Negeri 22 Semarang Tahun Ajaran 2013/2014. https://lib.unnes.ac.id/20086/1/1301409060. $p d f$.

Siregar, N.R. 2017. Persepsi siswa pada pelajaran matematika: studi pendahuluan pada siswa yang menyenangi game. http://jurnal.unissula.ac.id/index.php/ippi/art icle/download/2193/1655.

Soleha. 2010. Pengaruh Motivasi Belajar Terhadap Hasil Belajar Matematika. Jurnal Pendidikan MIPA Vol 1. No 1. Page 24. http://jurnal.umpalembang.ac.id/kognisi/article/download/12 $2 / 95$.

Sugiyono. 2014. Tanggapan Masyarakat Terhadap Implementasi Kurikulum 2013. http://staffnew.uny.ac.id/upload/132296045/ penelitian/tanggapan-masyarakat- terhadapimplementasi-kurikulum-2013.pdf.

Suarga. 2017. KERANGKA DASAR DAN LANDASAN PENGEMBANGAN KURIKULUM 2013. Volume VI, Nomor 1. 
http://portalriset.uinalauddin.ac.id/bo/upload/penelitian/penerbit an_jurnal/Suarga\%20IP\%2 02017\%20Vol.1.pdf

Subiyantoro, S., Nugroho, A. A. 2019. PENGEMBANGAN MEDIA

PEMBELAJARAN BERBASIS ANDROID SEBAGAI PENDUKUNG PEMBELAJARAN MATA KULIAH BELAJAR DAN PEMBELAJARAN. Vol 3 No

3.

http://ojs.iptpisurakarta.org/index.php/Edudi kara/article/view/12

Fauziah, Amni , dkk. 2017 . Hubungan Antara Motivasi Belajar Dengan Minat Belajar Siswa Kelas Iv Sdn Poris Gaga 05 Kota Tangerang.

file:///C:/Users/DELL/Downloads/959423174-1-SM.pdf

Falahudin, Iwan. 2014. Pemanfaatan Media dalam Pembelajaran.
https://juliwi.com/published/E0104/Paper01 04_104-117.pdf

Steffi, Adam, \& Syastra, TM . 2015. Pemanfaatan Media Pembelajaran Berbasis Teknologi Informasi Bagi Siswa Kelas X Sma Ananda Batam

file:///C:/Users/DELL/Downloads/400-611008-1-10-20180307.pdf

Nurcikawati. 2018. Rancang Bangun Media Pembelajaran Trigonometri Berbasis Multimedia Interaktif. Vol 4 No 2 (2018). http://jurnal.ustjogja.ac.id/index.php/sosio/ar ticle/view/2766.

Octafiana, W., Ekosusilo, M., \& Subiyantoro, S. (2018). PENGEMBANGAN MULTIMEDIA INTERAKTIF PADA MATERI PESAWAT SEDERHANA UNTUK SISWA SEKOLAH DASAR. Jurnal Komunikasi Pendidikan, 2(2), 168175. 